\title{
Application of FACTS devices for flexibility control of transmission networks
}

\author{
Irina Kolosok ${ }^{1, *}$, Elena Korkina $^{2}$, and Alexander Tikhonov ${ }^{2}$ \\ ${ }^{1}$ Melentiev Energy Systems Institute of SB RAS, Irkutsk,Russia \\ ${ }^{2}$ RUSAL Engineering and Technological Center, LTD, Irkutsk, Russia
}

\begin{abstract}
Maintenance of power balance at each time moment in every node and in the electric power system as a whole is a mandatory condition for supplying the electric power of required quality (frequency, voltage levels). Property of the system to be considered as its ability to control power balance is referred to as flexibility. Technologies for operating conditions control or systems services are an efficient means of regulating the flexibility of HV transmission networks in the cycle of on-line and anti-emergency control. Present-day FACTS of the second generation based on power electronics whose control systems ensure high efficiency of control and stabilization are the most perspective means of flexibility regulating and control. The paper considers potentials of using those devices for regulating the flexibility of 500/200 kV network that is a section of a real EPS. Calculations were performed in the simulation experiment and were based on real telemetry measurements using the State Estimation Software.

The results of the studies have showed that substitution of the first-generation FACTS devices by the controlled second-generation FACTS devices and installation of new present-day FACTS allows notable enhancement of HV electric networks controllability and ensures the required level of networks flexibility.
\end{abstract}

\section{Introduction}

Energy industry development on the base of innovation technologies radically changes the structure and properties of electric power systems (EPS). EPS flexibility is defined as EPS ability to maintain normal or close to normal operating conditions under the effect of internal (sudden changes and fluctuations of the load, load flows in the lines, and fluctuations in generation), external (sudden disturbances of different origin), and random factors [1-3, et al.]. Introduction of a larger number of renewable energy sources and gradual transition from centralized energy supply systems to distributed ones lower the energy system stability, reliability, and flexibility.

According to [4], flexibility can be defined as ability of the system to ensure power balance control in every node and in the entire EPS. Power balance in the node may be maintained by changing the generating capacity, load capacity, by use of energy storage, and by changing the load flows in the outgoing lines. FACTS (Flexible Alternative Current Transmission System) technology allows better use of transfer capabilities of transmission lines, real-time change of load flows and practically instant response to EPS disturbances. Large-scale use of FACTS technologies and devices will notably enhance the EPS controllability and, hence, their flexibility, stability and survivability [5].

The paper considers potentials of using those devices for regulating the flexibility of $500 / 200 \mathrm{~kW}$ network that is a section of a real EPS. For integrating the FACTS into the network equivalenting scheme, the models of those devices developed in ISEM SB RAS were used [6]. Calculations were performed in the simulation experiment and were based on real telemetry measurements using the State Estimation software.

Results of investigation have shown that replacement of obsolete FACTS devices of the first generation by controllable devices of the second generation and installation of new present-day FACTS devices allows notable enhancement of HV electric networks controllability, and ensures the required level of networks flexibility.

\section{EPS flexibility analysis}

For ensuring the required reliability level at reasonable costs the dispatching personnel needs real-time information on the available EPS flexibility. The main approaches to the flexibility analysis are based on decomposition of the EPS calculation scheme into transmitting (high-voltage) and distribution subsystems $[7,8]$.

Some papers published abroad [9-10] introduce two notions for the EPS flexibility analysis: operational and local flexibilities. Operational flexibility is ability of the energy system to damp faults in order to maintain safe operating conditions. The most frequent faults are interruptions in operation due to disconnection of a line or a generator, and errors in power generation forecast.

Corresponding author: kolosok@isem.irk.ru 
Locational or nodal flexibility is flexibility that can be ensured by a concrete node of the network. Local flexibility is described explicitly by permissible deviations in the conditions parameters and is characterized by marginal disturbances that can be balanced in this node.

For the analysis of nodal flexibility the possible deviations in the conditions parameters (capacity of conventional and renewable generating sources, load capacity, etc.) from scheduled values specified by dispatching curves and check of observing the technological and modal constrains after their implementation are modeled. This analysis identifies the size of disturbance in a particular node that can be liquidated by affordable corrective actions. These actions include repeated dispatcher's measures, such as deployment of reserves, demand system management, and changes in the network topology.

System's flexibility can be analyzed and modeled for different time intervals. They may be:

1. Daily interval, i.e., flexibility analysis and planning for a day ahead;

2. Inter-day interval when flexibility is analyzed and planned for the period from one hour to several hours;

3. In real-time when system's behavior is monitored continuously and relative changes in curves of working points specified at previous stages are analyzed.

\subsection{FACTS as a means for flexibility regulating}

The main flexibility provision and regulating means at different levels of present-day energy systems include the following devices and technologies for EPS control [7]:

1. Flexibility regulating on the generation side;

2. Demand System Management;

3. Operating conditions control technologies (systems services);

4. Energy storages;

5. Virtual regulating systems (aggregation of loads, energy storages, electro mobiles, etc.);

6. Technologies of energy markets;

7. Advanced technologies ("power-to-heat" $(\mathrm{P} 2 \mathrm{H})$ for renewable energy sources (RES), power-to-gas (P2G) and hydrogen, vehicle-to-grid (V2G)).

Technologies for operating conditions control or systems services are an efficient means of HV transmitting networks flexibility control in the cycle of real-time and anti-emergency control. Development of present-day EPS provides for large-scale introduction of FACTS technology. FACTS technology and devices unlock new opportunities for EPS control as they ensure monitoring of interrelated parameters of the scheme and conditions. Present-day FACTS of the second generation based on power electronics whose control systems ensure high efficiency of control and stabilization are the most perspective means for flexibility regulating and provision. They primarily may include $[12,13]$ :
- A steady-state synchronous compensator (STATCOM) that is a thyristor-controlled reactive power source maintaining the set voltage value by consumption or generation of reactive power in the point of connection without use of additional external reactors or high-capacity capacitor banks;

- A thyristor-controlled series compensator (TCSC) that is a reactive capacitor consisting of a capacitor bank connected to the line in series, and connected in parallel with a thyristor-controlled reactor to ensure gradual change of capacitive reactance;

- A phase shifter that is a phase shifting transformer monitored by thyristor control to ensure rapid change in the phase shift angle;

- A unified power flow controller (UPFC) that unites characteristics of three devices: STATCOM, TCSC and phase shifter that helps it to solve different tasks of reactive and active power flow control: to increase transfer capacity of transmission lines, to correct reactive impedance of a line, to correct the phase shift angle, to maintain voltage at a given level;

- A DC link on voltage converters is a converter substation for AC conversion into DC and subsequent DC conversion into AC of default or any other frequency.

High response speed of those devices is their major characteristic that is provided for by the use of presentday high-speed converters and executive systems on the base of power electronics, which allows their use in the run-time control of EPS.

\section{A proposed approach for transmission network flexibility analysis}

An approach proposed for transmission network flexibility analysis is based on provisions set forth in [9] and consists in the following:

1. For describing the transient behavior of EPS with energy storages a mathematical EPS model proposed in [9] was developed in the form of the first-order discrete-time differential equations Technological constraints and conditions parameters are set.

2. Systems disturbances for each node are modeled as deviations of conditions parameters (generations and loads in the node) from values specified in the dispatcher's schedule.

3. Steady-state conditions are calculated and adequacy of the obtained steady-state conditions to technological constraints is checked.

4. If the obtained operating conditions are admissible, i.e., all the constraints are met, then the checked node has a sufficient flexibility degree for given disturbances.

5. If systems constraints are not met, then we calculate 'new' steady-state conditions whose parameters lie 
within the permissible limits using the operating conditions regulating means available in this node, i.e., changing the generation and/or load capacity, storage capacity available at a given time moment, and load flows on the outgoing lines. This evidences that control means available in the node ensure flexibility of this node. Otherwise this node has no required flexibility degree.

6. If control means available in EPS do not produce operating conditions meeting the requirements of technological constraints at given disturbances, then maximum permissible disturbances are determined at which the obtained steady-state conditions are admissible.

Calculations as per Items 2-5 are performed on-line and allows one to estimate of operational flexibility of a system on the base of individual contributions of local flexibilities of all the nodes. Calculations as per Item 6 are performed off-line and are not considered in the present paper.

At this stage of investigation we offer one to perform the off-line analysis of nodes flexibility using the state estimation results for a certain time period based on the data available in the archive for this time period as default conditions (estimated values of voltages, loads, generations).

For performing the computations in the conventional model of a node in the form of active power balance equations used in the EPS state estimation problem it is necessary to take into account RES generation, capacity of energy storage, and process dynamics. Such a model for $\mathrm{k}$-th node can be represented by a differentialdiscrete in time first-order equation (in our notation) [9]: $C\left(x^{k, t+1}-x^{k, t}\right)+P_{\text {gen }}^{k, t}-P_{\text {load }}^{k, t}-\sum_{j \in \omega_{k i}} P_{k j}^{t}=0$,

where $\mathrm{C}$ is energy storage capacity in the $k$-th node, $x$ is a state of energy storage charge in the k-th node at a time moment $\mathrm{t}$, load reduction/increase $P_{\text {gen }}^{k, t}$ is generation capacity in the $\mathrm{k}$-th node that includes generation of conventional and renewable energy sources, $P_{\text {load }}^{k, t}$ is load capacity in the $k$-th node , $\sum_{j \in \omega_{k i}} P_{k j}^{t}$ - a sum of active power flows in the lines outgoing from the $k$-th node.

\subsection{Check of locational flexibility}

When modeling the conditions for checking the flexibility of separate nodes we use the active power margins in loaded generator nodes, constraints on voltage in the loaded nodes, and transmitted power margins in the controlled cross-sections and lines:

$0 \leq P_{\text {load }}^{k, t} \leq P_{\text {load }}^{k, \max }$,

$P_{\text {gen }}^{k, \min } \leq P_{\text {gen }}^{k, t} \leq P_{\text {gen }}^{k, \max }$

$U_{\text {load }}^{k, \min } \leq U_{\text {load }}^{k, t} \leq U_{\text {load }}^{k, \max }$,

$P_{k j}^{t} \leq P_{k j}^{\max }$,

Modeling of disturbances is performed when solving the EPS state estimation problem:
- Reduction/increase of generation or load in the node $\mathrm{k} \Delta P^{k, t}$ within the limits specified by conditions (1), (2) that leads to redistribution of load flows (change in the value $P^{k, t}=P_{\text {gen }}^{k, t}-P_{\text {load }}^{k, t}=\hat{P}^{k, t}+\Delta P^{k, t}, \quad$ where $\quad \hat{P}^{k, t}$ is power generation and consumption at balanced operating conditions);

- $\quad$ Disconnection of the line that leads to crucial load flow redistribution;

- Constraints (3) and (4) are used as technological constraints when calculating the operating conditions after modeling the disturbances.

\subsection{Check of operational flexibility}

Flexibility analysis outcome is a list of nodes with sufficient degree of systems (operational) flexibility. If in the course of modeling in the considered node as a result of state estimation the technological limits of operating conditions parameters are violated, the node cannot be categorized as flexible one.

After the system (network) analysis for operating and local flexibility, a list of nodes that in the considered period are not sufficiently flexible is compiled. Those nodes shall be analyzed regarding potentials for enhancing the flexibility property, e.g., replacement of generating equipment by more powerful one, unloading the node by load redistribution, involvement of additional power sources (RES and energy storages).

\section{Computational example}

Use of CSC and TCSC for voltage control and for increasing the transmission line's (TL) transfer capability

For checking the proposed technique a segment of a real 500/200 kW EPS was used (Fig. 1).

In the computational scheme there are two generating nodes - they are large-scale HPP - and six load nodes, the remaining nodes being transit ones. Power from generating sources to areas with high industrial and residential load is transmitted via two parallel $500 \mathrm{kV}$ lines.

Steady-state stability margin for two $500 \mathrm{kV} 700 \mathrm{~km} \mathrm{TL}$ made $\sim 1950 \mathrm{MW}$, whereas for meeting the industrial and other loads to a consumer of the first-grade (special) load area, about $2900 \mathrm{MW}$ was to be transmitted via TL. Therefore, in the $70-\mathrm{s}$ of the previous century a compensation device (CSC) was installed on those lines, which allowed increase in the marginal flow to the required value and ensured required voltage level in the load nodes 1, 2 and 5. It is worth mentioning that some other FACTS of the first generation (shunt reactors, synchronous compensators, and filter-compensating devices) were installed on such a long and sophisticated TL. 


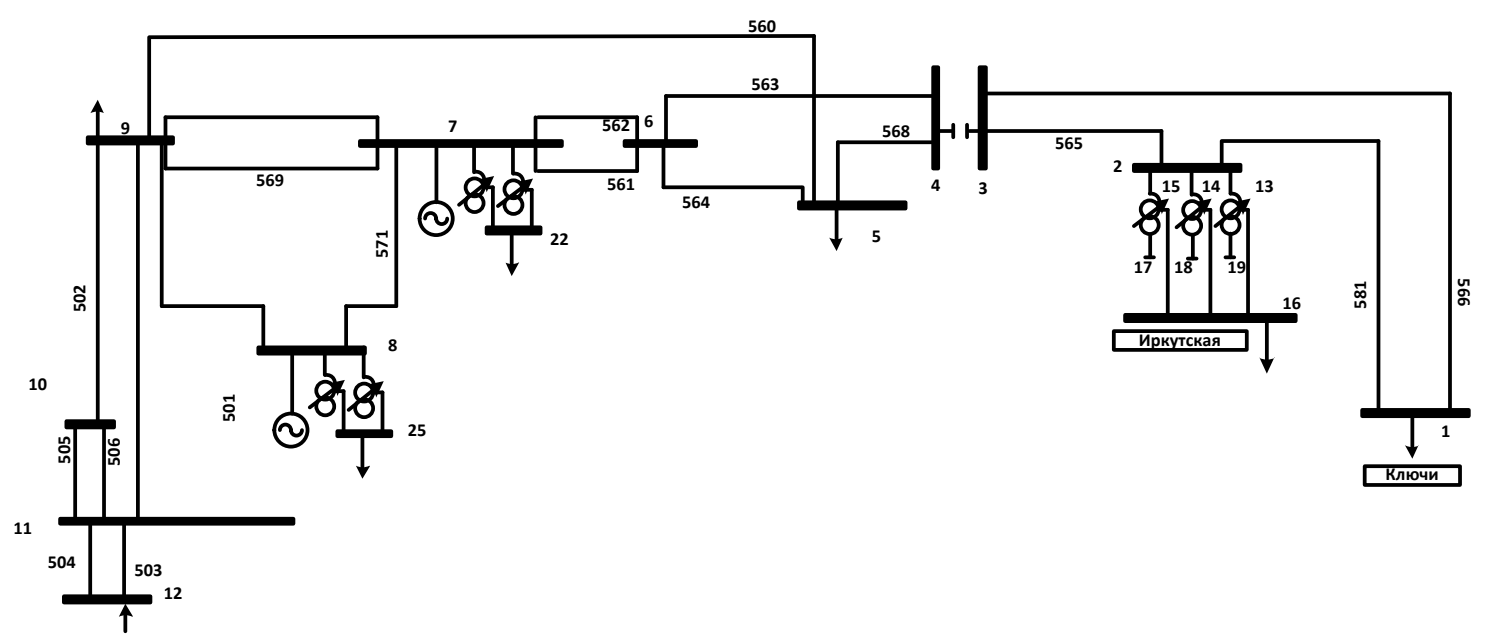

Fig. 1. 25-node scheme of a power system

CSC is a capacitor bank, i.e., bridges connected to the network in series; the total number of bridges is four. In the steady-state calculations and in the state estimation problems CSC is modeled by a branch with negative reactance and minimum resistance. Bridges connection and disconnection allows reactance control in the $500 \mathrm{kV}$ network, thus defining the value of a marginal active power flow. Reactive power generated by CSC cannot change smoothly that is not acceptable for EPS stability during transmission of high power. For series compensation of reactive power the synchronous capacitors were applied that at that time were the only FACTS ensuring smooth change in the value of consumed power that depends on the excitation winding current. This solution allowed us to increase the transfer capability of a transit line and to transfer 1611 MW thus ensuring the required voltage level at the most remote substations (nodes 1 and 2).

But CSC use impedes frequent run-time switching. Use of TCSC is an alternative. A part of a capacitor bank in it is shunted by a thyristor controller that allows smooth change of its equivalent capacity depending on the operating conditions of a line.
Emergency load drop by $200 \mathrm{MW}$ was modeled in Node 1. It caused voltage growth in all the nodes that is not allowable when using CSC as capacitor banks constituting CSC are rather sensitive towards high voltage and are destroyed at a voltage above $523 \mathrm{~kW}$.

Calculations showed that integration of TCSC into the equivalenting scheme instead of discretely controllable CSC device (branches 3-4) allows maintenance of the required voltage level in case of emergency load drop.

When transmitting $1611 \mathrm{MW}$ via $500 \mathrm{kV}$ transit line, $\mathrm{CSC}$ has full capacitive reactance $\mathrm{X}_{\mathrm{CSC}}=-26.3 \mathrm{Ohm}$; this value was taken as initial approximation in computations with TCSC. Table 1 presents the main parameters of operating conditions 'before' and 'after' the load drop.

Results of calculation show that if TCSC is used, the degree of series compensation changes with the change of transmitted power due to emergency load drop. For transmission of $1611 \mathrm{MW}$ it is necessary to compensate $500 \mathrm{kV}$ transit line reactance (nodes $7-1$ ) by $-21.79 \mathrm{Ohm}$ in the default conditions and by $-7.613 \mathrm{Ohm}$ at load drop and transmission of $1407 \mathrm{MW}$. Series reactance when using TCSC changes smoothly and does not generate additional transient processes, and allows conditions monitoring within the permissible voltage limits.

Table 1. Comparable calculation of using CSC and TCSC in case of emergency load drop.

\begin{tabular}{|c|c|c|c|c|c|c|}
\hline \multirow[b]{2}{*}{ Node/Line } & \multirow[b]{2}{*}{ Parameter } & \multirow[b]{2}{*}{ Units } & \multicolumn{2}{|c|}{ CSC } & \multicolumn{2}{|c|}{ TCSC } \\
\hline & & & $\begin{array}{c}\text { Normal } \\
\text { conditions }\end{array}$ & $\begin{array}{l}\text { Emergency } \\
\text { load drop }\end{array}$ & $\begin{array}{c}\text { Normal } \\
\text { conditions }\end{array}$ & $\begin{array}{l}\text { Emergency load } \\
\text { drop }\end{array}$ \\
\hline 1 & $\mathrm{P}$ & MW & 413 & 207 & 410 & 207 \\
\hline 1 & Q & Mvar & 45 & 23 & 44 & 23 \\
\hline 1 & $\mathrm{U}$ & $\mathrm{kV}$ & 506 & 522 & 504 & 511 \\
\hline 2 & $\mathrm{U}$ & $\mathrm{kV}$ & 504 & 519 & 502 & 507 \\
\hline 3 & $\mathrm{U}$ & $\mathrm{kV}$ & 521 & 530 & 519 & 519 \\
\hline 4 & $\mathrm{U}$ & $\mathrm{kV}$ & 522 & 537 & 519 & 520 \\
\hline $3-4$ & $\mathrm{x}$ & Ohm & -26.3 & -26.3 & -21.79 & -7.613 \\
\hline $3-1$ & $\mathrm{P}$ & MW & 683 & 579 & 681 & 580 \\
\hline $3-1$ & Q & Mvar & 3 & -63 & 4 & -48 \\
\hline $3-2$ & $\mathrm{P}$ & MW & 930 & 827 & 928 & 827 \\
\hline $3-2$ & $\mathrm{Q}$ & Mvar & 96 & 23 & 97 & 40 \\
\hline
\end{tabular}




\section{Conclusions}

Technologies for operating conditions control or systems services are an efficient means of HV transmitting networks flexibility control in the cycle of real-time and anti-emergency control.

Present-day FACTS of the second generation based on power electronics whose control systems ensure high efficiency of control and stabilization are the most perspective means of flexibility regulating and control.

High-speed response of FACTS is their important feature that allows their use in the real-time EPS control. Application of series compensators whose degree of compensation grows with the transmitted power increase has a positive impact on system's conditions in terms of voltage and reactive power, whereas uncontrollable devices need frequent switching.

Results of investigation have shown that replacement of obsolete FACTS devices of the first generation by controllable FACTS devices of the second generation and installation of new devices allows notable enhancement of HV electric networks controllability and ensures the required level of networks flexibility.

The work has been done under financial support of Russian Science Foundation grant no. 19-49-04108 "Development of innovation technologies and means for flexibility assessment and enhancement in the future energy systems".

\section{References}

1. Cochran J., Miller M., Zinaman O., Milligan M., e.a. Flexibility in 21st Century power systems // 21st Century Power Partnership, Denver,USA, Clean Energy Ministerial, 2014, pp. 1-14.

2. Lannoye E., Flynn D., O’Malley M. Evaluation of power system flexibility // IEEE Trans. PowerSyst., 2012, Vol. 27, No. 2, pp. 922-931.

3. Voropai N., Rehtanz Ch Flexibility and Resilience of Electric Power Systems: Analysis of Definitions and Content EPJ Web Conf. 2019 International Workshop on Flexibility and Resiliency Problems of Electric Power Systems (2019)

4. Zubakin V., Opadchy F., Kuleshov M., Arhipov A., Shevchenko S. Impact of projects on demand monitoring on power price change on the example of VINK// Energorynok, № 7, 2019.

5. Voropai N.I., Kolosok I.N., Korkina E.S., Osak A.B. Problems of vulnerability and survivability of cyber-physical and electric power systems // Energy Policy, Vyp. 5, 2018, pp. 53-61.
6. Kolosok I.N., Tikhonov A.V. Modeling the FACTS devices when estimating the state of a segment of $500 \mathrm{kV}$ network of IPS of Siberia // Proc. Of Intern. Sci.-Practical Workshop "Methodological issues of studying the reliability of large energy systems', Vyp. 69 "Reliability of developing energy systems", Book 1, Irkutsk: ISEM SB RAS, 2018, pp. 209218.

7. Haeger U., Rehtanz Ch., Voropai N. ICOEUR project results on improving observability and flexibility of large-scale transmission systems // IEEE PES General Meeting, San Diego, USA, July 24-29, 2012, 7 p.

8. Ulbig A., Andersson G. Analyzing operational flexibility of electric power systems // 18th Power System Computation Conference, Wroclaw, Poland, August 25-28, 2014, 8 p.

9. Bucher M.A., Delikaraoglou S., Heussen K., Pinson P., Andersson G., "On quantification of flexibility in power systems", 2015 IEEE Power Tech, Eindhoven, Netherlands, June 29 - July 2, 2015, $6 \mathrm{p}$.

10. Zhao J., Zheng T. and Litvinov E. A Unified Framework for Defining and Measuring Flexibility in Power System // IEEE Trans. On Power Syst., January 2015, 31(1), pp.1-9.

11. Peter D. Lund, Juuso Lindgren, Jani Mikkola, Juri Salpakari, Review of energy system flexibility measures to enable high levels of variable renewable electricity (Renewable and sustainable energy reviews, V. 45, 2015, pp. 785-807.

12. Foundation of the present-day energy industry. In 2 volumes. V. 2 Present-day energy industry: Text book for higher educational inst./Edited by Corr. Member of RAN E.V. Ametistov 5Th edition, updated.-M.: MEI Publishers - 2010. - 632 p.: Figs. (66)

13. Acha E., Fuerte-Esquivel C. R., Ambriz-Perez H., Angeles-Camacho C. FACTS. Modelling and Simulation in Power Networks. England:John Willey \& Sons. Ltd, 2004. - 420 p. 